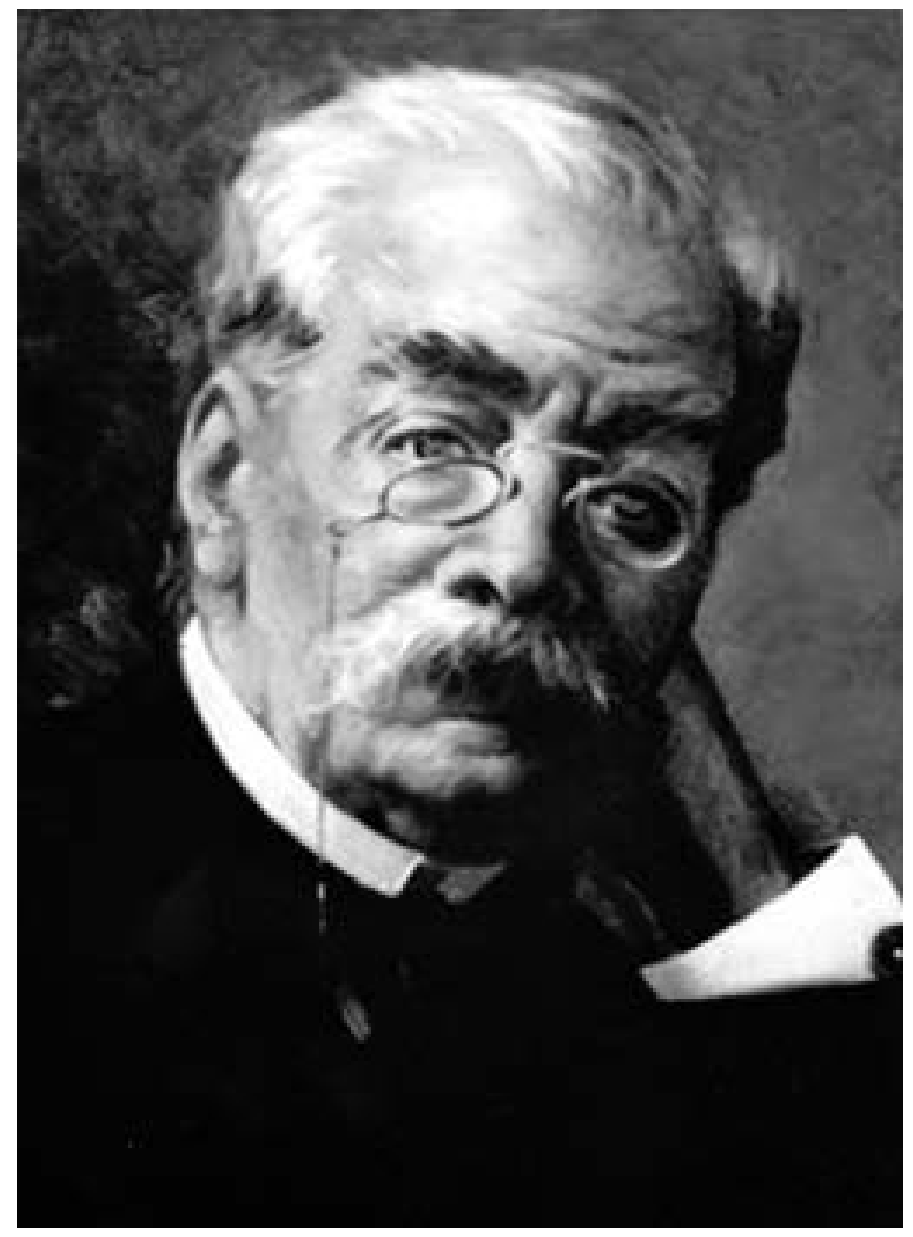




\section{UN AMIGO DE RICARDO PALMA: Celso Víctor Torres}

Dr. César Ángeles Caballero

\section{Itinerario biográfico}

Celso Víctor Torres, "Palma ancashino", nació en Caraz (Villa San Idelfonso, capital de la Provincia de Huaylas) el 28 de julio de 1860 del matrimonio de Eusebio Torres y Antonia Figueroa. Interesan poco los detalles de su instrucción primaria y secundaria, menos aún su quehacer administrativo; sí vale referimos a la circunstancia que ejerciera la Escribanía del Estado desde I 888, porque, acaso, en el trajinar cotidiano de viejos y empolvados papeles y causas judiciales pudo captar la variable temática de sus Tradiciones caracinas. Tras el diario ejercicio de escribano, a partir de 1903, amplía la frecuencia judicial con el ejercicio de la notaría pública, hasta su fallecimiento acaecido el 12 de noviembre de 1918, a las nueve treinta de la mañana en la propia ciudad de Caraz. (Torres Guerrero, 1957, pp. 19-13)

Torres, además de tradicionista, cultivó el periodismo en La Prensa de Huaylas, diario fundado en 1893 por Javier Ramírez; Variedades, importante revista limeña de Clemente Palma. No soslayables son sus colaboraciones para La Opinión Nacional y El Tiempo; también sus escarceos poéticos, publicados por el bibliógrafo hispano Carlos Prince, bajo el título de Nueva Colección de Yaravíes y Huaynos Peruanos y que el citado editor volvió a publicar en 1903, con el simple rótulo de Yaravíes y huaynos, en selección de cuarenta y cinco canciones (p. 55 ). Torres calificó a estos versos de "obra chabacana", Prince lo registra en su Boletín bibliográfico, puntualizando en el prólogo de la segunda edición: "cada nota es un agudo puñal que atraviesa de punta a punta el corazón”. (El Correo del Perú, diciembre de 1875)

\section{Entrañable amistad epistolar}

La carta, vehículo prodigioso de la palabra escrita, vinculó extraordinariamente a dos almas gemelas; de un lado "El Patriarca de las Letras Peruana", exponente ensimismado de su Lima virreinal proyectiva; de otro el olvidado notario Celso V. Torres, espíritu inquieto, absorbido por el medio aisladamente cultural de su tierra nativa y solo respaldado por la hermosura de su paisaje eucapiltazo y níveo. Pese a los quinientos kilómetros, entre la paz todavía bucólica de Miraflores y el rumor apacible, eglógico de Caraz, la amistad cultivase fecunda y pródiga. Probablemente 
las epístolas intercambiadas suman varias decenas, la inicial masiva de torres, data del 22 de junio de 1898. Párrafos importantes por el contenido pueden ser estos:

No puede Ud. imaginarse cuán grata ha sido para mí la recepción de su anhelada del I I del actual que me es grato contestar, enorgulleciendo que ella sea autógrafa y haya merecido mi anterior contestación suya.

Amargo desengaño encierra la modestia de ud. al negarme el drama Rodil cuya maestra fecunda poesía me había entusiasmado. Paciencia, pero he logrado mayor ventaja con hacerme suyo.

Cinco días luego, 27 de junio de 1898, como parte de su fructífera colaboración Celso V. Torres escribe a don Ricardo, enviándole noticias y datos de los ajetreos amorosos de Simón Bolívar en Huaylas y Caraz, al retrotraer sus cuitas con Manolita Madroño ("La Vieja de Bolívar", en la ancianidad recordatoria).

\section{Tímida influencia torresana en Palma}

Ciertas informaciones, sugerencias y datos enviados por Torres, Palma utilizó y transformó en tradiciones:

- " "Las tres etcéteras del Libertador", tradición palmiana, bebida en la carta de julio de 1898, según información de Torres. ${ }^{3}$

- "Los coronguinos, cuyos datos, al parecer histórica, fueron enviados en carta de 19 de julio de 1898. Palma ofrece en esta tradición, el proceso judicial formulado contra un burro por el Juez de Paz, Macario Remuzgo, que según la información epistolar de Torres, se trataba del Juez de Primera Instancia don Fernando Villarán.

- "Un santo varón", proviene de la epístola fechada el 16 de agosto de 1898, según la cual anunciaba Torres la remisión de la "Historia Aciselo al Verdugo", sin embargo, señala la carta: "... pero aquí otra, que suplico a Ud. se sirva arreglarla para su publicación: "Un Viernes Santo en Caraz" que trata de Mercedes Damaris (a) Huisco Mercedes en sus extravagancias como organista y su torpeza al servir de Santo Varón en la Iglesia de San Idelfonso de Caraz, el año de 1862...", asunto que jocosamente, Palma, convirtió en "Un santo varón".

- "Quién toca el arpa"; los informes se originan en la carta del 6 de setiembre de 1898, Palma oculta el nombre de la ciudad donde acaecen los hechos (Caraz) y cambia los personajes auténticos (Juan Sáenz y Zoila Vega de la referencia de 
Torres) por Juan Pérez y Zoila Véjar. Aclarando, mayormente el sentido de esta tradición. Torres envió a Palma dos notas más.

En la primera, 5 de febrero de 1900, puntualiza. "Así, ¿Quién toca el arpa? Será refrán universal dentro de breve"; y en la segunda de 24 de octubre de 1900.

Incuestionablemente que Palma sintió especial deferencia por Áncash, justificable debido a la amistad con el caracino Torres y su breve permanencia en Huaraz en 1867, desempeñando la Secretaría del Coronel D. José Balta, que bien aprovechó en la captación del argumento de su tradición "la justicia en Bolívar", así como de la denominada "El primer gran Mariscal del Perú"'; es decir Don Toribio de Luzuriaga. Del apego por Ancash, provienen las tradiciones "Un fanático"2, "A muerto me huele el godo", "Una aventura amorosa del Padre Chueca"4,

"El médico inglés"5, "La Conga"6. Esta narra pasajes de la campaña revolucionaria de Balta, transitoriamente en Áncash y "La gran querella de los barberos de Lima".

\section{Reflejo palmista en Torres}

Acontece también lo inverso. Celso V. Torres, se vale de las tradiciones de Palma, para completar las suyas, como en las tituladas: "En las noches de San Juan", "La Noche Buena", "Pregones de Lima", "Los pericotes" y "La temeridad y la justicia de Dios", esta última dedicada a don Ricardo Palma, y publicada en la revista Variedades ${ }^{7}$. En carta del 14 de julio de 1917 Torres señala:

Al leer su tradición "A muerto me huele el godo", me palpitó de gozo el corazón porque en ella creo haber encontrado el espeluznante final de una tragedia horrorosa sucedida en el pueblo de Mato, a dos leguas Norte de esta ciudad de Caraz, en los comienzos del siglo XIX.

Mi tradición "la temeridad y la justicia de Dios" se ha mantenido inédita, porque me faltaba el corolario o fin del protagonista, que lo encuentra en "A muerto me huele el godo", que con venia de Ud. voy a copiar para completar este ligero trabajo. Creo que la una no excluye a la otra, ni pueden desdeñarse, perdonándome Ud. que merodee en sus propiedades; que "probada la necesidad y utilidad es precedente la expropiación forzada".

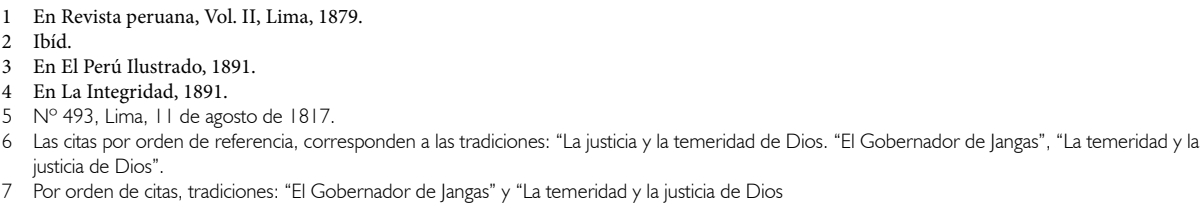


Acepte Ud. mi querido don Ricardo, que con respetuoso cariño le haga esta declaratoria su antiguo colaborador y amigo.

\section{Bagaje tradicional: perspectiva en su género}

Medio centenar de tradiciones escribió Celso V. Torres aproximadamente, la mayoría de ellas publicadas en La Prensa de Huaylas, algunas en la exigente revista Variedades y en otras revistas limeñas. Sobresalen:

- " "La Semana Santa en Casma"

- "28 de julio"

- "Las sandalias de fray Velarde"

- "Matrimonio por prescripción"

- " "Una respuesta primorosa"

- "Finanzas de Uniperio"

- "Una postura en Fa"

- "Rempuja o un Quijote Peruano"

- "El puente del asno"

- "Malambo"

- " "La carta del doble efecto"

- "En las noches de San Juan"

- "la Noche Buena"

- "Los pericotes"

- "Huata"

- "El gobernador de Jangas"

- "La fiesta del Milagro"

- "28 de julio de antaño"

- "Barrio de Arequipa (ipor qué se denomina Arequipa a una sección de Caraz?)"

- "Ortografía"

- "Los soberanos de antaño" 
Celso V. Torres es tradicionista, casi plenamente desconocido, pese a su fecundidad temática, perspectiva en su género y el inigualable bagaje estilístico bebido en palma. Consideramos buenos imitadores de don Ricardo a la cuzqueña Clorinda Matto de Turner, al arequipeño Mariano $H$. Cateriano, sin reparar en que lo más próximo y excelente radica en el olvidado caracino Celso V. Torres, a quien justicieramente denominamos "El Ricardo palma ancashino".

La especial circunstancia de que Celso V. Torres fuera dilecto amigo de don Ricardo Palma, constituye móvil proficuo y ferviente anhelo de escribir tradiciones al estilo palmista. Los temas manejados por el caracino, bebidos en facetas históricas a través de personajes epocales del autor, aproxima aún más al tradicionista limeño, viable en la estructura misma del discurrir utilizado por Torres. Remarcada influencia puede encontrarse en ciertos rasgos estilísticos: con usufructo de comparaciones. Torres, como Palma, alardea el empleo de comparaciones, para acrecentar las afirmaciones intrínsecas del contenido argumental:

"bella hasta la eternidad" (por extremadamente hermosa", "cacerista de tuerca y tornillo" (cacerista total e indubitable", "hogar, que era un rincón del paraíso" (hogar perfecto en lo espiritual y bello en lo material). ${ }^{7}$

a. Senda coplera. Característica fundamental del estilo romantizado de las Tradiciones peruanas, radica en el sagaz empleo de coplas, engarzadas de intimidad amorosa y piropesca. Torres hace lo propio; vale citarse el caso más representativo cuando hilvana versos arreglados de la musa popular:

La hermosura de los cielos:

Cuando Dios la repartió.

No estarías tú muy lejos,

Cuando tanto le tocó

(La temeridad y la justicia de Dios).

b. Sinonimia etimológica. Ciertos vocables son sustituidos por términos de semejanza interpretativa de calidades: "los esposos arriesgaban la pelleja" (pelleja por vida, en sentido total de protección); "encariñado en su conjunta" (conjunta equivalente a esposa o mujer, sinonimia aquella de compenetración, totalidad e institucionalidad matrimonial) $)^{8}$.

7 Citas de las tradiciones: "La temeridad y la justicia de Dios", las dos primeras y las tres últimas de "El Gobernador de Jangas". 
c. Frecuenta adjetivación. La adjetivación es no menos frecuente, implicando reiteración de cualidades: "sexo barbudo"; "golosos hijos de Adán"; "roñoso robo de gallinas", "sufrió la pena negra", "alocar al mismísimo cachazudo Job"9

d. Sentencioso alarde. Torres, como Palma su maestro de estilo, entresaca sentencias del hablar popular coloquial, acogiendo su honda preocupación folklórica, para vertebrar cristalina y socarronamente en sus tradiciones con ánimo sutilmente burlón y con cierta carcajada costumbrista que hace vibrar satíricamente el ajetreo de sus personajes, a través de expresiones teñidas de malicia y gracejo: "las bolas que corrían"; "no picó tan alto"; "sencillamente un tono de capirote"; "poniendo los pies en plovorosa"; "un abrí y cerrar de ojos"; "al musulmán Vicente se le subió la pimienta a la nariz"; o dejar caer aquello de "Al fin al Santo Patrón de Jangas hizo un milagrito: lo iluminó..." ${ }^{\text {. }}$

\section{Actitud complementaria}

De la obra de Torres, embebida de tradicionismo, no solo interesa la excelente imitación, ni su alarde de notable captación palmista, sino también aquel otro matiz, singularmente perdurable, palpitando en la actitud complementaria asumida a lo largo de la historia tradicional: "La temeridad y la justicia de Dios", que en orden cronológico y de características constituye la primera parte de la tradición de Palma, "a muerto me huele el godo", cuyo tema es el triste fin de un "viejezuelo", al que Torres se atreve llamarlo Vicente, maestro de escuela en 1823, en el pueblo de Pichagua (provincia de Armaraes), según Palma. De su lado, Torres, en su tradición ya citada señala que en la tradición "A muerto me huele el godo", "cree haber encontrado el espeluznante final de una tragedia horrorosa sucedida en el pueblo de Mato..." (Áncash).

Probable es que Ricardo palma se valiera de un relato efectuado por "un respetable anciano que fue alférez en el Imperial Alejandro, número 45", tomando artificiosamente el nombre de Huaylas cuando los hechos se efectuaron en el pueblo de San Jacinto de Mato o Villa Sucre, a tres leguas al norte de la ciudad de Caraz, ciudad esta donde nació, residió, escribió y murió Celso V. Torres, la primera parte de la tradición que ambos maneja, valiéndose Palma de las informaciones que captó Torres.

Colígese finalmente que Torres se aproxima a Palma: en el estilo y técnica literaria de esgrimir las tradiciones; en la temática eminentemente peruanista: mezcla de ligera 
crónica, narrativa o novela, "halago de historia tradicional", empleo de peruanismos, giros idiomáticos, frases populares o en el criollismo al reproducir asuntos costumbristas, reviviendo acaeceres semihistóricos, pergeñados en el terruño y eslabonando "un poco de verdad y ciento de mentira". Celso Torres es, por todo lo expresado, uno de los genuinos valores de la literatura ancashina, si bien imitador de Palma, pero con calidad y recuerdos propios, que nadie puede escamotear. Ha dejado apreciable cantidad de tradiciones, por ahora perdidas en la prensa ancashina y alguna en la revista limeña Variedades.

\section{Sobre unas picantes tradiciones}

Que Ricardo Palma escribió unas salpimentadas tradiciones, subidas de tono humorístico y teñidas además de cierto matriz pornográfico no cabe la menor duda. De nuestro lado conocemos desde hace más de veinte años la existencia de dichas tradiciones, y lo que aquí diremos respecto a ellas, es fruto de nuestro personal investigación, al mismo tiempo que un anticipo de un estudio más extenso. Pero, también es conveniente anotar que este conocer, no solo nos concierne a nosotros, sino que otros escritores peruanos también las conocen, en especial Esteban Pavletich, quien penetra aguda y sugestivamente sobre este menester, cuando escribe aludiendo de entrada la denominación de Tradiciones en salsa verde.

Tampoco he podido leer esa colección de composiciones de tradicionista, no obstante su difundida circulación con copias mecanográficas, aún entre escolares, Tengo entendido que hace algunos años se imprimió con ellas un folleto, aparentemente en prensas de Huaraz, lo que pudo ser una treta del editor clandestino para borrar mejor su huella." (Aguilar, 1967, pp. 58-59).

Precisamente, queremos acotar datos de interés complementarios de estas referencias, aludidas por Pavletich, como una separación singular.

El origen temático de algunas de las Tradiciones en salsa verde, provienen de la entrañable amistad de Palma con el tradicionista caracino Celso V. Torres, especialmente la titulada "la p. del libertador", que se originó en la carta del 12 de julio de 1898. Palma escribe en base de los datos suministrados por Celso V. Torres, aquella tradición. El 5 de agosto de aquel año, Torres agradece la epístola de Palma y el envío de la corrección.

Por informe de Palma, nos enteramos que la colección constó de veinticinco tradiciones, de las que efectuó dos copias, obsequió una a Celso V. Torres y la otra a Carlos Vasadre (febrero de 1904), con especial encargo de no impresión, ni copia. 
Las tradiciones en salsa verde enviadas por Palma a Torres, son extraordinariamente interesantes, tanto en el lenguaje coloquial empleado, cuando en la temática. Fueron enviadas con la siguiente dedicatoria:

Al amigo don Celso Víctor Torres le obsequió, para que las lea únicamente a personas de íntima confianza esta tradiciones que, por su sabor pornográfico, no debe imprimirse - Lima, 1890. Ricardo Palma.

\section{Llevan por título:}

- La p... del Libertador

- La consigna del General Sucre

- Un desmemoriado

- iTejo o tajo?

- El clavel disciplinado

- La moza del Gobierno

- Los inocentes

- Arroz con pato

- El carajo de Sucre

Bien aduce Pavletich, siguiendo un estudio del profesor norteamericano David Reedy:

Según asegura el profesor Reedy, basándose en una carta que le dirigiera un familiar del moreno escritor.

El deseo de la familiar de Palma es de proteger el prestigio literario de don Ricardo, el cual se temía fuese mancillado si estos trabajos se expusieron al público.

Pero estos argumentos perogrullescos, teñidos de escarceos de beatas, carecen de valor, y no deben empañar el conocimiento de las citadas tradiciones, pues de ellas

Se extraería , también, tal vez, en forma de no admitir dudas, la auténtica posición de Palma en relación con la Colonia, con la República, con la España colonial, con los líderes de las luchas por la emancipación, aunque no sean indios ni mestizos, y conoceríamos estas palabras escatológicas y expresiones fuertes... 
De ahí entonces y como lógica consecuencia, acotamos una vez más:

¿Que esas piezas son subidas de color? Si son amenas, ligeras y chistosas, como las mejores de sus tradiciones, las licencias que Palma se toma en ellas no tendrían la menos importancia. En algunos de sus plurales fuentes -el arcipreste de Hita y el de Talavera, Bocaccio, Fernando de Rojas, el obispo Guevara, Pero Mexia, Rodríguez Freyle, el abate Casti-, abundan las escabrosidades. La única condición es que no dejen de ser artistas. Ya Wilde sentenció que no hay libros morales o inmorales sino buenos o malos. Lo que exigimos es que se nos muestra únicamente la media cara de la moneda, un Palma depurado, seleccionado, recién salido de la peluquería (Esteban Pavletich).

Está, además, por reiterar el hecho vital, de que Celso V. Torres proporcionó abundantes datos para algunas de las Tradiciones en salsa verde, comprobable a través de un continuo y eslabonado intercambio epistolar, pues según carta del 12 de julio de 1898, Torres escribe:

Siempre que yo quite a Ud. su tiempo remitiéndole estos datos, se dignará decirme de los que merezcan su aprobación y que ocupan las páginas de sus hermosas tradiciones.

Palma, el pie de esta carta, anotó sencillamente: “D. Celso Torres me envió una serie de cartas, muy entretenidas. Varios de sus relatos me han dado tema para escribir algunas tradiciones" (Palma, 1949, p. 338).

De las Tradiciones en salsa verde que Palma obsequiara a Torres, indudablemente que la más sabrosa, por sus cuatro costados, es la denominada "La p... del Libertador", y cuyo final, decía así:

Y no quisiera Ud. doña Cila, la p... del Libertador?

Y la jamona que, como mujer, no era colchonable (hace falta la palabra en el diccionario), considerando que quizá se trataba de alguna alhaja u objeto curioso codiciable, contestó sin inmutarse:

- Dejándomela a buen precio, también recibo la p... 


\section{Referencias bibliográficas}

El Correo del Perú. Diciembre de 1875. Lima

El Perú llustrado, |89|.

La Integridad, I89I. No 493. Lima, II de agosto de 1817.

Revista Peruana ( I 879), Vol. II, Lima.

Revista peruana, Vol. II, Lima, 1879.

Torres Guerrero, A. (1957). Tradiciones caracinas. Caraz: Atun Huaylas. 